\title{
Clinical features and survival of pregnancy- associated breast cancer: a retrospective study of 203 cases in China
}

\author{
Bo-yue Han ${ }^{1,2 \dagger}$, Xiao-guang Li ${ }^{2,3 \dagger}$, Hai-yun Zhao ${ }^{2,3 \dagger}$, Xin Hü ${ }^{2,3}$ and Hong Ling ${ }^{1,2^{*}}$
}

\begin{abstract}
Background: Pregnancy-associated breast cancer (PABC) is an aggressive disease, and since Chinese authority began to encourage childbearing in 2015, the incidence of PABC has increased. This study investigated the characteristics and survival of PABC patients.
\end{abstract}

Methods: Patients with PABC who underwent surgery at Fudan University, Shanghai Cancer Center between 2005 and 2018 were enrolled. Data concerning the tumor characteristics, maternal state (whether first or nonfirst pregnancy) and survival outcome were recorded. Pearson Chi-square tests were used to compare the characteristics of the tumors, and Kaplan-Meier methods were used to perform the survival analysis.

Results: Overall, 203 PABC patients were recruited. Since 2015, 65.5\% of non-first pregnant women were diagnosed with breast cancer, it's 5.7 fold of the incidence of PABC in non-first pregnant women. No significant differences in tumor characteristics were observed between the patients who were in their first pregnancy and those in non-first pregnancy. Among the entire PABC population, luminal B breast cancer accounted for the largest proportion (38.4\%), followed by triple-negative breast cancer (TNBC, 30.0\%). The distribution of the molecular subtypes of PABC and non-PABC differed $(P<0.001)$ as follows: in the PABC patients, Luminal B 38.4\%, Triple negative breast cancer (TNBC) 30.1\%, Human Epidermal Growth Factor Receptor 2 (HER-2) overexpression 15.8\%, and Luminal A 10.8\%; in the non-PABC patients, Luminal A 50.9\%, Luminal B 20.1\%, TNBC 17.4\%, and HER-2 overexpression 8.0\%. The 3-year disease free survival (DFS) of all PABC patients was $80.3 \%$. The 3 -year DFS of the patients in the first-pregnancy group was $78.4 \%$, and that of the patients in the non-first-pregnancy group was $83.7 \%(P=0.325)$.

Conclusions: Our study proved that the proportion of women who developed PABC during the second or third pregnancy was extremely high relative to the newborn populations. The patients in the PABC population tended to present more luminal $B$ and TNBC breast cancer than the non-PABC patients.

Keywords: Pregnancy-associated breast cancer, First-pregnancy, Non-first-pregnancy, Lactation, Survival

\footnotetext{
* Correspondence: linghong98@aliyun.com

${ }^{\dagger}$ Bo-yue Han, Xiao-guang Li and Hai-yun Zhao contributed equally to this work.

'Department of Breast Surgery, Fudan University Shanghai Cancer Center, Fudan University, 270 Dong-an Rd, Shanghai 200032, China

${ }^{2}$ Department of Oncology, Shanghai Medical College, Fudan University, Shanghai 200032, China

Full list of author information is available at the end of the article
}

(C) The Author(s). 2020 Open Access This article is licensed under a Creative Commons Attribution 4.0 International License, which permits use, sharing, adaptation, distribution and reproduction in any medium or format, as long as you give appropriate credit to the original author(s) and the source, provide a link to the Creative Commons licence, and indicate if changes were made. The images or other third party material in this article are included in the article's Creative Commons licence, unless indicated otherwise in a credit line to the material. If material is not included in the article's Creative Commons licence and your intended use is not permitted by statutory regulation or exceeds the permitted use, you will need to obtain permission directly from the copyright holder. To view a copy of this licence, visit http://creativecommons.org/licenses/by/4.0/ The Creative Commons Public Domain Dedication waiver (http://creativecommons.org/publicdomain/zero/1.0/) applies to the data made available in this article, unless otherwise stated in a credit line to the data. 


\section{Background}

Breast cancer is the most common cancer among women [1]. Pregnancy-associated breast cancer (PABC) is defined as breast cancer diagnosed during pregnancy or within 1 year after pregnancy [2]. PABC is a very rare type of cancer. The incidence of PABC reportedly ranges from 0.2 to $3.8 \%[3,4]$.

In October 2015, Chinese authority abolished the restriction in which a couple can have only one child to actively address the aging of the population. Subsequently, we observed a sharp increase in PABC at our center, and non-first pregnancies accounted for a large proportion, which attracted our attention. However, a thorough understanding of this problem is lacking; thus, we performed an investigation of PABC in the Chinese population. We enrolled 203 women treated at Fudan University, Shanghai Cancer Center (FUSCC) to study the clinical characteristics and prognosis of PABC patients.

\section{Patients and methods Participant eligibility}

In this retrospective study, we reviewed the medical records of patients who underwent surgery between January 2005 and December 2018 at the Department of Breast Surgery, FUSCC. The eligible patients included women who had regional invasive unilateral breast cancer, with their first symptoms occurring during pregnancy or lactation. The lactation period usually refers to the first year after childbirth. Patients diagnosed with stage IV breast cancer or previously diagnosed breast cancer, ductal or lobular atypical hyperplasia, sarcomas or phyllodes tumors were excluded from our study (Fig. S1). We also enrolled women who were diagnosed with breast cancer at FUSCC during the same period to compare the molecular subtypes $(n=43,721)$. This retrospective study was approved by the Ethics Committee Review Board of FUSCC (050432).

\section{Data collection}

All patients diagnosed with PABC between January 2005 and December 2018 were enrolled in this study. To analyze the clinicopathological characteristics of PABC patients, the study variables included the age of the patients, gestational period at the appearance of the first symptoms (months), family history of breast cancer, surgery type and other treatments (adjuvant/neoadjuvant chemotherapy, radiotherapy, endocrine therapy and target therapy), pathologic tumor size, lymph node status, histological grade, estrogen receptor (ER) and progesterone receptor (PR) status, expression of human epidermal growth factor receptor-2 (HER-2), expression of Ki-67, etc. A status of either ER or PR positive was defined as hormone receptor (HR) positive.
The data of all recruited patients were collected for the PABC characteristic analysis. For the survival analysis, patients diagnosed with PABC after 2016 were excluded to ensure a follow-up time longer than 3 years. Disease-free survival (DFS) was defined as the time between the first date of diagnosis to any locoregional recurrence, including ipsilateral breast, local/regional lymph nodes of the disease, any contralateral breast cancer, any distant metastasis of the disease, or any secondary malignancy, whichever occurred first $[5,6]$.

\section{Statistical analysis}

Pearson Chi-square tests were used to compare the histopathological characteristics of the tumors and clinical features of the patients among the different subgroups. The Kaplan-Meier methods were used to perform the survival analysis. All tests were two-sided, and a $P$-value less than 0.05 was considered statistically significant. All statistical analyses were performed using SPSS statistical software version 25.0 package (IBM Corporation, Armonk, NY, USA).

\section{Results}

\section{General information}

In total, 203 patients were diagnosed with PABC between 2005 and 2018 in FUSCC, and the median age of the study population was 33 years (range, 23 years to 46 years). The population was divided into the first-pregnancy group, which included women with breast cancer during the pregnancy or lactation period of their first child, and the non-first-pregnancy group, which included women with PABC during the pregnancy or lactation period of their second, third or greater child. Among the patients, 79 (38.9\%) women developed breast cancer during their first pregnancy period (first-pregnancy group), and 124 (61.1\%) women were assigned to the non-first-pregnancy group. Since 2015, 65.5\% of non-first pregnant women were diagnosed with breast cancer, while only $25 \%$ of newborns were non-first births in Shanghai (according to the China Health and Wellness Development Statistics). Thus, the incidence of PABC among non-first pregnancy women was 5.7-fold higher than that among first-pregnancy women.

\section{Tumor characteristics}

Table 1 shows the distribution of the tumor characteristics according to the first/non-first pregnancy subgroups. The first-pregnancy group was younger than the non-first-pregnancy group $(P<0.01)$. The proportion of HR-positive tumors in the firstpregnancy group was $57.0 \%$, while the proportion in the non-first-pregnancy group was $47.6 \%(P=0.281)$. In the first-pregnancy group, the proportion of HER- 
Table 1 Patient characteristics and tumor characteristics according to first and non-first pregnancy subgroup

\begin{tabular}{llllll}
\hline Endocrine therapy & & & & & 0.281 \\
Yes & 45 & 57.0 & 59 & 47.6 & \\
No & 34 & 43.0 & 61 & 49.2 & \\
Target therapy & & & & & 0.757 \\
Yes & 17 & 21.5 & 29 & 23.4 & \\
No & 62 & 78.5 & 95 & 76.6 & \\
\hline
\end{tabular}

Abbreviations: HR Hormone receptor, HER-2 Human epidermal growth factor receptor-2, IDC Invasive ductal carcinoma, DCIS Ductal carcinoma in situ, ILC Invasive lobular carcinoma, SLNB Sentinel lymph node biopsy, ALND Axillary lymph node dissection, $p C R$ Pathological complete remission

(a): HR positive: ER (estrogen receptor) positive or/and PR (progesterone receptor) positive

(b): Pearson Chi-square tests between first pregnancy group and non-first pregnancy group

2-positive tumors was $26.6 \%$, while that in the nonfirst-pregnancy group was $36.3 \%(P=0.108)$.

Among all patients, $23(11.3 \%)$ patients chose to terminate their pregnancies and receive immediate treatment (abortion group), 66 (32.5\%) patients were diagnosed with PABC during pregnancy and chose to delay treatment until the fetus was born (non-abortion group), and the remaining 114 (56.2\%) PABC cases were diagnosed during the lactation period (lactation group) (Table S1).

\section{Molecular subtypes}

Among the entire PABC population, luminal B breast cancer accounted for the largest proportion (38.4\%), followed by triple-negative breast cancer (TNBC, 30.0\%). Compared with PABC, the non-PABC patients showed a significant distribution of molecular subgroups as follows: luminal A breast cancer was the most common (50.9\% in non-PABC vs. $10.8 \%$ in PABC, $P<0.001$ ), followed by luminal $B$ breast cancer $(20.1 \%$ in nonPABC vs. $38.4 \%$ in PABC, $P<0.001$ ). The proportion of both TNBC and HER-2 overexpression breast cancer was much smaller in the non-PABC patients $(17.4 \%$ in non-PABC vs. $30.1 \%$ in $\mathrm{PABC}, P<0.001 ; 8.0 \%$ in non$\mathrm{PABC}$ vs. $15.8 \%$ in $\mathrm{PABC}, \mathrm{P}<0.001$, respectively) (Fig. 1 ). It was demonstrated that a greater proportion of patients with PABC had the luminal B and TNBC types of cancer. A trend similar to that observed in the total PABC population was observed in both the first-pregnancy group and non-first pregnancy group (Fig. 1).

\section{Treatments}

Compared with the non-first-pregnancy group, the firstpregnancy group preferred to delay treatment until the fetus was born (proportion of non-abortion cases: $85.7 \%$ vs. $68.9 \%, P=0.092$ ). The times from initial symptoms to initiation of treatment in the first-pregnancy and non- first-pregnancy groups were 6.20 months and 4.67 months, respectively $(P=0.106)$.

In total, 196 (96.6\%) women received adjuvant/neoadjuvant chemotherapy, and anthracycline combined taxane chemotherapy (53.5\%) was the most commonly used regimen. Among the patients, 84 patients received neoadjuvant chemotherapy, and 18 (21.4\%) patients achieved a pathologic complete response (pCR). Although trastuzumab was recommended for all patients with HER-2 overexpression tumors, not all patients could afford the high cost. Among the patients with HER-2 overexpression tumors, 46 (69.7\%) patients received trastuzumab as the target therapy (Table S1).

\section{Survival analysis}

Among all patients diagnosed with PABC before 2016, the median follow-up period was 59.0 months (range, 2 months to 144 months). The 3-year disease free survival (DFS) of all PABC patients was $80.3 \%$, the DFS of the patients in the first-pregnancy group was $78.4 \%$, and the DFS of the patients in non-first-pregnancy group was $83.7 \%$ ( $P=0.325$, Fig. 2a). The 3-year DFS in the pregnancy (abortion) group, pregnancy (non-abortion) group and lactation group was 86.2, 74.4 and $85.4 \%$, respectively $(P=0.278$, Fig. $2 b)$.

\section{Discussion}

We reviewed 25 studies conducted over the past 20 years to gain a deeper understanding of PABC (Table 2). The incidence of PABC reportedly ranges from $0.2-3.8 \%$ [3, $4,6]$. PABC used to be a rare disease in China. However, recently, the number of cases increased. In our study, we observed that the frequency of PABC in non-first pregnancy women has increased as women started to have second children since Chinese authority abolished the restriction that couples could only have one child. Our study found that the proportion of PABC developed in non-first pregnancy women was 5.7-fold higher than that developed in first-pregnancy women. We reviewed the literature and found a study conducted in Taiwan that enrolled 26 PABC patients, and most patients $(n=$ 18) were first-pregnancy women [30]. These inconsistent results may be due to the small enrollment number. As the largest breast center in East China, our center has treated more than 6000 primary breast cancer patients per year, ensuring less bias in our study. Other than the above-mentioned study, we found no other studies mentioning the difference in the incidence of PABC between first-pregnancy women and non-first pregnancy women.

In our study, we observed a significant difference in the molecular subtypes between the PABC and nonPABC cases. Luminal B breast cancer accounted for the largest proportion of all PABC patients, followed by triple-negative breast cancer. Consistent with our study, 
$1 \mathrm{~A}$

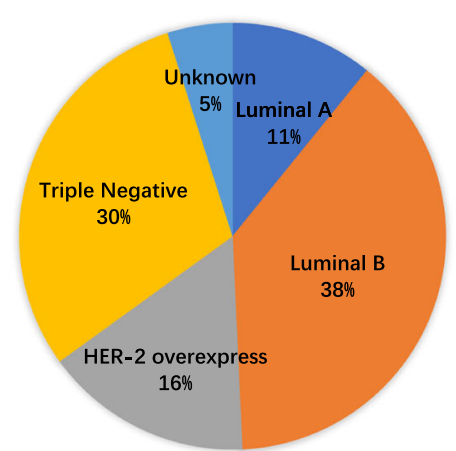

- Luminal $A=$ Luminal $B=$ HER-2 Overexpress $₫$ Triple Negative $\approx$ Unknown

$1 \mathrm{C}$

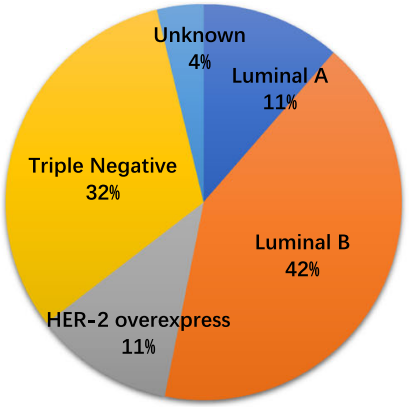

- Luminal $A=$ Luminal $B=H E R-2$ Overexpress $\equiv$ Triple Negative $\equiv$ Unknown
1B

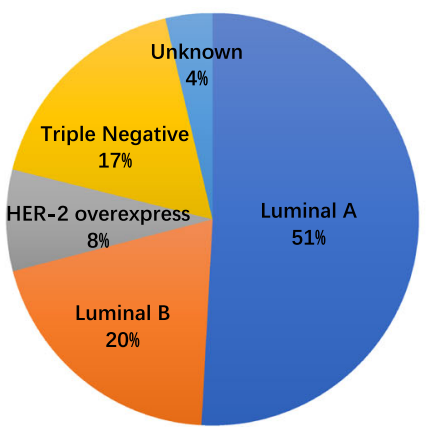

- LuminalA $=$ LuminalB $=$ Her-2 Overexpress $₫$ Triple Negativa $₫$ Unkown

$1 \mathrm{D}$

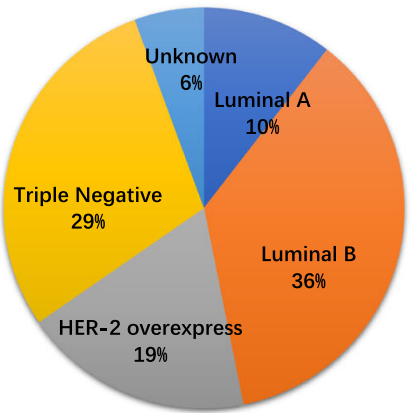

=Luminal $A=$ Luminal $B=H E R-2$ Overexpress $₫$ Triple Negative $\approx$ Unknown

Fig. 1 Molecular subtypes of the PABC, breast cancer other than PABC, PABC developed in women's first pregnancy and non-first pregnancy. a Molecular subtypes of the PABC, $n=203$. b Molecular subtypes of breast cancer other than PABC (non-PABC), $n=43,721$. $\mathbf{c}$ Molecular subtypes of the PABC developed in women's first pregnancy (First-Pregnancy subgroup), $n=79$. $\mathbf{d}$ Molecular subtypes of the PABC not developed in women's first pregnancy (Non-First-Pregnancy subgroup), $n=124$. The $P$ value was less than 0.001 , by using Pearson Chi-square tests to compare the distribution of molecular subtypes in PABC patients (a) and non-PABC patients (b),

demonstrating a difference. The $P$ value was 0.554 , by using Pearson Chi-square tests to compare the distribution of molecular subtypes in First-pregnancy group (c) and Non-first-pregnancy group (d), demonstrating no statistical significance. PABC=Pregnancy-associated breast cancer; $E R=$ Estrogen Receptor; $P R=$ Progesterone Receptor; HER-2 = Human Epidermal Growth Factor Receptor-2, HR (Hormone Receptor) +: Either ER or PR+. Luminal A: ER+, PR+, HER-2 (-), Ki-67<14\%; Luminal B: HR+, Ki-67 214\%; HR+, HER-2(+); ER+, PR-; Her-2 overexpression: HR (-), HER-2 (+); TNBC (Triple negative breast cancer): ER (-), PR (-), HER-2 (-)

Soo reported that luminal B breast cancer $(43.6 \%)$ and TNBC (35.9\%) predominated in PABC [24]; while one study presented a different conclusion and showed that TNBC ranked first (48.4\%) [20]. Some studies did not list the molecular types but reported the HR and HER-2 status and demonstrated that $\mathrm{PABC}$ was more prone to be HR-negative tumors, but no difference in the HER-2 status was reported compared with non-PABC as follows: HR negative $(50.0 \%$ in PABC vs. $36.1 \%$ in nonPABC, $P<0.001$ (Yun et al.)) [25], HR negative (32.6\% in PABC vs. $15.9 \%$ in non-PABC, $P=0.014$ (Jessica et al.)) [22], and HR negative $(59.4 \%$ in PABC vs. $34.4 \%$ in nonPABC, $P=0.03$ (Michael et al.)) [31]; only one study reported by Soo showed a higher HER-2 positive rate in PABC patients as follows: HER-2 positive $38.5 \%$ in PABC vs. $19.2 \%$ in non-PABC, $P=0.006$ ) [29]. Although these views vary, all studies indicated that $\mathrm{PABC}$ tended to present with more aggressive tumors.
The 3-year disease free survival (DFS) of all PABC patients at FUSCC was $80.3 \%$. We reviewed the literature, and the survival of PABC patients reportedly fluctuates over a large range. Wagner reported a very low survival as follows: 5 -year overall survival (OS) of $29.7 \%$ and 10 year OS of $19.2 \%$ among PABC patients [28]; however, Carole showed that the 5 -year OS was $87.5 \%$ and that the 10-year OS was $70.0 \%$ [29]. The survival rates of the PABC patients compared to those of the non-PABC patients were conflicting. Most studies [15, 16, 18-21, 23$26,28,32]$ demonstrated a worse prognosis in PABC after excluding prognostic factors, including age, the tumor size, and lymph node status, while eight studies [7-14] showed no difference in survival between PABC and non-PABC patients after correcting for these factors.

Our analysis showed that the Kaplan-Meier survival curve of the first-pregnancy group was below that of 

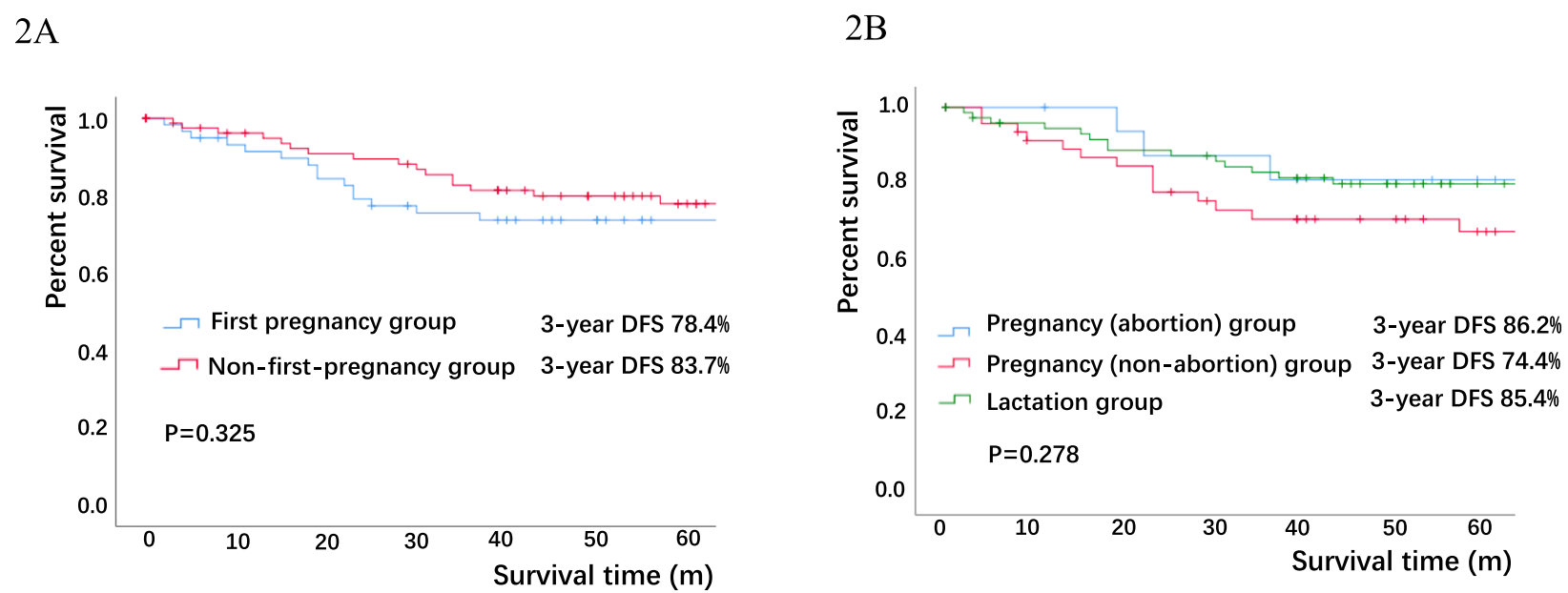

Fig. 2 Survival of PABC patients in different subgroups. a Comparison of 3-year DFS of patients with PABC developed in their first pregnancy (first pregnancy group) and PABC developed in non-first pregnancy. b Survival curve of patients with PABC developed in pregnancy phase and underwent abortion (abortion subgroup), in pregnancy phase but no abortion (non-abortion group) and PABC developed in lactation phase. The 3-year DFS was estimated between First-pregnancy group and Non-first-pregnancy group by Log-rank test with a P value of 0.325. The 3-year DFS was estimated among among Pregnancy (non-abortion) subgroup, Pregnancy (abortion) subgroup and Lactation subgroup of PABC by Logrank test with a $P$ value of 0.278. PABC=Pregnancy Associated Breast Cancer; DFS = Disease Free Survival

the non-first-pregnancy group. However, there was no statistically significant difference. We speculate that the two groups might have survival differences, but these differences are unclear in this study due to the rare incidence and limited case number. We have no supporter. We will collect more cases to make it clear in 10 years.

Five studies classified PABC into antepartum and postpartum breast cancer, and three studies showed that the prognosis of PABC occurring postpartum was worse than that of $\mathrm{PABC}$ occurring during gestation $[17,30$, 31]; Mathelin concluded that the prognosis of PABC occurring during the antepartum period was worse [29]; and Daling indicated that PABC occurring postpartum had a worse survival rate than non-PABC [27]. The survival analysis in our study showed no difference. In our study, we found that patients in early pregnancy were more likely to terminate their pregnancies, while those in late pregnancy usually preferred to delay treatment until the delivery of the fetus.

Starting chemotherapy in mid-late pregnancy without delaying chemotherapy until after delivery is generally preferred as unnecessary delays may result in a worse prognosis. FAC (fluorouracil, adriamycin and cyclophosphamide) is a commonly used chemotherapy regimen that has been shown to be safe in mid-late pregnancy [33]. Doxorubicin and cyclophosphamide can be excreted through milk and, therefore, are prohibited during lactation [33]. However, in China, people generally do not undergo chemotherapy during mid-late pregnancy. Mid-pregnancy women with PABC choose to either terminate the pregnancy or delay chemotherapy until delivery, while late-pregnancy women usually start chemotherapy treatment after delivery. In our study population, 20 (30.3\%) PABC patients with HER-2 positivity did not receive Herceptin treatment, including 18 (85.7\%) patients who were diagnosed with PABC before 2017. In China, Herceptin was not included in the scope of medical insurance reimbursement until 2017.

It should be acknowledged that there were some limitations in our present study. This study was a single-center study. The follow-up of the patients in the non-first-pregnancy group was short because the restriction was abolished in 2015. We could only obtain the 3-year DFS data. Moreover, some tumor characteristics were absent. The HER-2 status of 9 people was unknown probably because the patients refused to undergo further FISH analyses due to the high cost at that time.

\section{Conclusions}

In conclusion, our study proved that the incidence of PABC developed during the second or third pregnancy was higher than that developed in women's first pregnancy. The patients in the PABC population tended to present more luminal $B$ and TNBC breast cancers than the non-PABC patients. Our single-center study provides some information regarding the characteristics and survival rates of $\mathrm{PABC}$ patients. However, further research investigating $\mathrm{PABC}$ in a large population and investigations of the physiological mechanisms is needed in the future. 


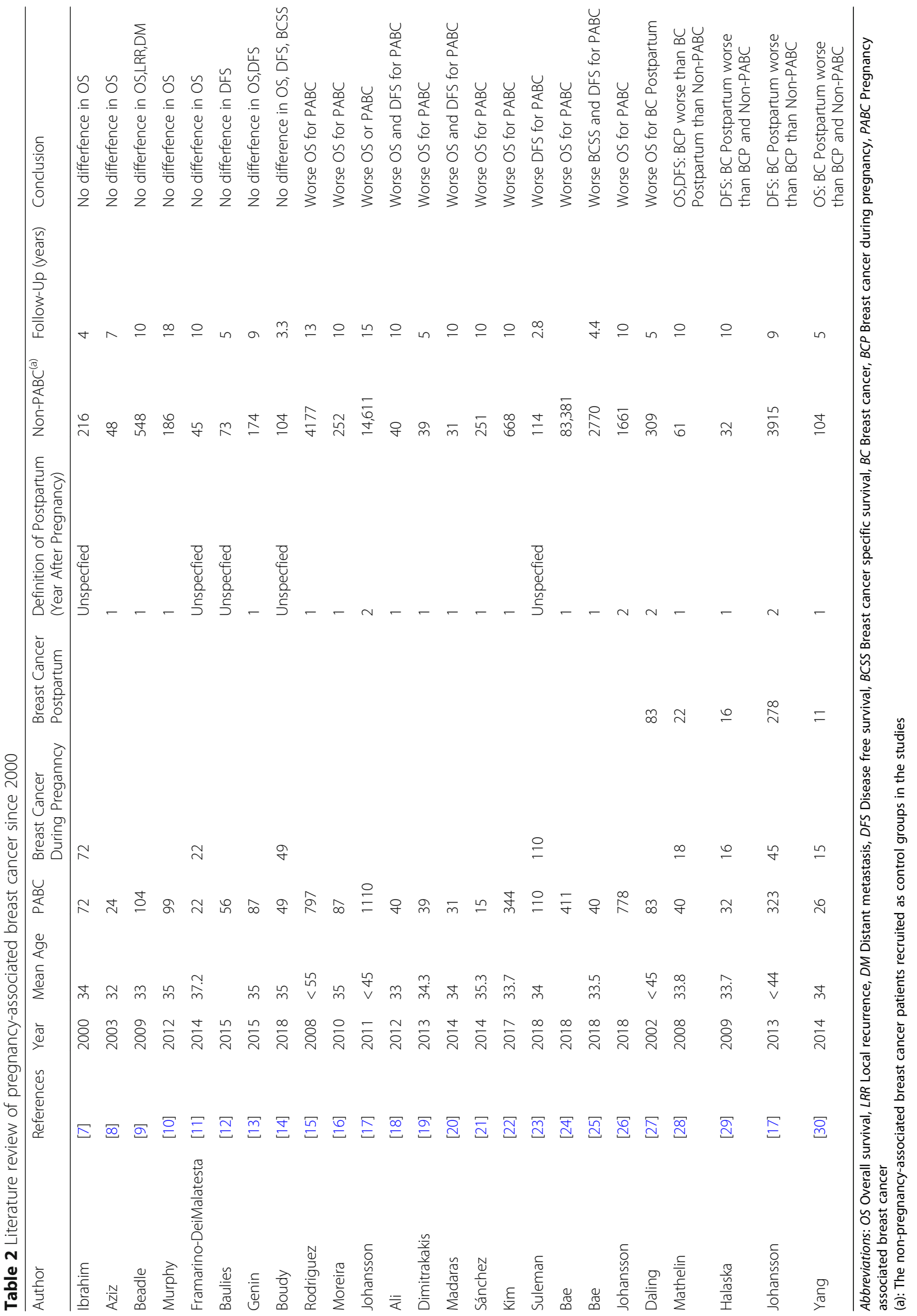




\section{Supplementary information}

Supplementary information accompanies this paper at https://doi.org/10. 1186/s12885-020-06724-5.

Additional file 1: Figure S1. Flow chart of patient selection. FUSCC= Fudan University Shanghai Cancer Center; PABC=Pregnancy-associated breast cancer.

Additional file 2: Figure S2. Molecular subtypes of the Pregnancy (non-abortion), Pregnancy (abortion) and Lactation subgroup of PABC. S2 A: Molecular subtypes of the Pregnancy (non-abortion) subgroup, $n=66$. S2 B: Molecular subtypes of the Pregnancy (abortion) subgroup, $n=23$. S2 C: Molecular subtypes of the Pregnancy Lactation subgroup, $n=114$. The $P$ value was 0.551 , by using Pearson Chi-square tests to compare the distribution of molecular subtypes in the Pregnancy (non-abortion) (S2 A), Pregnancy (abortion) (S2 A) and Lactation subgroup (S2 A) of PABC $\mathrm{PABC}=$ Pregnancy-associated breast cancer; $\mathrm{ER}=$ Estrogen Receptor; PR = Progesterone Receptor; HER-2 = Human Epidermal Growth Factor Receptor-2, HR (Hormone Receptor) (+): Either ER or PR (+). Luminal A: ER $(+)$, PR (+), HER-2 (-), Ki-67 < 14\%; Luminal B: HR (+), Ki-67 $\geq 14 \%$; HR (+), HER-2 (+); ER (+), PR (-); Her-2 overexpression: HR-,HER-2 (+); TNBC (Triple negative breast cancer): ER (-), PR (-), HER-2 (-)

Additional file 3: Table S1. Patient characteristics and tumor characteristics according to pregnancy (abortion), pregnancy (nonabortion) and lactation subgroup. (a): HR positive: ER (estrogen receptor) positive or/and PR (progesterone receptor) positive. (b): Pearson Chisquare tests between pregnancy (non-abortion) group and pregnancy (abortion) group (c): Pearson Chi-square tests between pregnancy (nonabortion) group and lactation group.

\section{Abbreviations}

PABC: Pregnancy-associated breast cancer; TNBC: Triple-negative breast cancer; HER-2: Human Epidermal Growth Factor Receptor 2; DFS: Disease free survival; FUSCC: Fudan University, Shanghai Cancer Center; ER: Estrogen receptor; PR: Progesterone receptor; HR: Hormone receptor; pCR: Pathologic complete response; FAC: Fluorouracil, adriamycin and cyclophosphamide

\section{Acknowledgements}

Not applicable.

\section{Authors' contributions}

$\mathrm{HL}$ and $\mathrm{XH}$ conceived and designed the study. BY $\mathrm{H}$ and $\mathrm{HY} \mathrm{Z}$ analyzed the data. XG L and BY H contributed reagents, materials, and analysis tools. BY H and $\mathrm{HZ}$ wrote the paper. All authors read and approved the final manuscript.

\section{Funding}

This work was funded by the National Natural Science Foundation of China (Grant number 81602311, 81672601 and 81872137) and Fudan University (Grant number 20043301). Funding bodies had no role in the study design, collection, analysis and interpretation of the data or in writing the manuscript.

\section{Availability of data and materials}

Not applicable.

\section{Ethics approval and consent to participate}

This study did not involve animals.

All procedures performed in studies involving human participants were in accordance with the ethical standards of the institutional and/or national research committee and with the 1964 Helsinki Declaration and its later amendments or comparable ethical standards.

This retrospective study was approved by the Ethics Committee Review Board of Fudan University Shanghai Cancer Center (050432), and the need to obtain informed consent was waived.

\section{Consent for publication}

Not applicable.

\section{Competing interests}

The authors declare that they have no competing interests.

\section{Author details}

${ }^{1}$ Department of Breast Surgery, Fudan University Shanghai Cancer Center, Fudan University, 270 Dong-an Rd, Shanghai 200032, China. ${ }^{2}$ Department of Oncology, Shanghai Medical College, Fudan University, Shanghai 200032, China. ${ }^{3}$ Department of Breast Surgery, Key Laboratory of Breast Cancer in Shanghai, Fudan University Shanghai Cancer Center, Fudan University, Shanghai 200032, China.

Received: 25 October 2019 Accepted: 6 March 2020

Published online: 23 March 2020

\section{References}

1. Bray F, Ferlay J, Soerjomataram I, Siegel RL, Torre LA, Jemal A. Global cancer statistics 2018: GLOBOCAN estimates of incidence and mortality worldwide for 36 cancers in 185 countries. CA Cancer J Clin. 2018;68(6):394-424. https://doi.org/10.3322/caac.21492.

2. Amant F, Loibl S, Neven P, Van Calsteren K. Breast cancer in pregnancy. Lancet. 2012;379(9815):570-9. https://doi.org/10.1016/s0140-6736(11)61092-1.

3. Wang B, Yang Y, Jiang Z, Zhao J, Mao Y, Liu J, Zhang J. Clinicopathological characteristics, diagnosis, and prognosis of pregnancy-associated breast cancer. Thorac Cancer. 2019. https://doi.org/10.1111/1759-7714.13045.

4. Hartman EK, Eslick GD. The prognosis of women diagnosed with breast cancer before, during and after pregnancy: a meta-analysis. Breast Cancer Res Treat. 2016;160(2):347-60. https://doi.org/10.1007/s10549-016-3989-3.

5. Hudis CA, Barlow WE, Costantino JP, Gray RJ, Pritchard Kl, Chapman JA, Sparano JA, Hunsberger S, Enos RA, Gelber RD, Zujewski JA. Proposal for standardized definitions for efficacy end points in adjuvant breast cancer trials: the STEEP system. J Clin Oncol. 2007;25(15):2127-32. https://doi.org/ 10.1200/JCO.2006.10.3523.

6. Vinatier $E$, Merlot B, Poncelet $E$, Collinet $P$, Vinatier D. Breast cancer during pregnancy. Eur J Obstet Gynecol Reprod Biol. 2009;147(1):9-14. https://doi. org/10.1016/j.ejogrb.2009.06.030.

7. Ibrahim EM, Ezzat AA, Baloush A, Hussain ZH, Mohammed GH. Pregnancyassociated breast cancer: a case-control study in a young population with a high-fertility rate. Med Oncol. 2000;17(4):293-300.

8. Aziz S, Pervez S, Khan S, Siddiqui T, Kayani N, Israr M, Rahbar M. Case control study of novel prognostic markers and disease outcome in pregnancy/ lactation-associated breast carcinoma. Pathol Res Pract. 2003;199(1):15-21. https://doi.org/10.1078/0344-0338-00347.

9. Beadle BM, Woodward WA, Middleton LP, Tereffe W, Strom EA, Litton JK, Meric-Bernstam F, Theriault RL, Buchholz TA, Perkins GH. The impact of pregnancy on breast cancer outcomes in women $<0 r=35$ years. Cancer. 2009;115(6):1174-84. https://doi.org/10.1002/cncr.24165.

10. Murphy CG, Mallam D, Stein S, Patil S, Howard J, Sklarin N, Hudis CA, Gemignani ML, Seidman AD. Current or recent pregnancy is associated with adverse pathologic features but not impaired survival in early breast cancer. Cancer. 2012;118(13):3254-9. https://doi.org/10.1002/cncr.26654.

11. Framarino-Dei-Malatesta M, Piccioni MG, Brunelli R, lannini I, Cascialli G, Sammartino P. Breast cancer during pregnancy: a retrospective study on obstetrical problems and survival. Eur J Obstet Gynecol Reprod Biol. 2014; 173:48-52. https://doi.org/10.1016/j.ejogrb.2013.11.017.

12. Baulies S, Cusido M, Tresserra F, Fargas F, Rodriguez I, Ubeda B, Ara C, Fabregas R. Biological and pathological features in pregnancy-associated breast cancer: a matched case-control study. Eur J Gynaecol Oncol. 2015; 36(4):420-3.

13. Genin AS, De Rycke $Y$, Stevens D, Donnadieu A, Langer A, Rouzier R, Lerebours F. Association with pregnancy increases the risk of local recurrence but does not impact overall survival in breast cancer: a casecontrol study of 87 cases. Breast. 2016:30:222-7. https://doi.org/10.1016/j. breast.2015.09.006

14. Boudy AS, Naoura I, Selleret L, Zilberman S, Gligorov J, Richard S, Thomassin-Naggara I, Chabbert-Buffet N, Ballester M, Bendifallah S, Darai E. Propensity score to evaluate prognosis in pregnancy-associated breast cancer: analysis from a French cancer network. Breast. 2018;40:10-5. https:// doi.org/10.1016/j.breast.2018.03.014.

15. Rodriguez AO, Chew H, Cress R, Xing G, McElvy S, Danielsen B, Smith L. Evidence of poorer survival in pregnancy-associated breast cancer. Obstet Gynecol. 2008;112(1):71-8. https://doi.org/10.1097/AOG.0b013e31817c4ebc.

16. Bae SY, Kim SJ, Lee J, Lee ES, Kim EK, Park HY, Suh YJ, Kim HK, You JY, Jung SP. Clinical subtypes and prognosis of pregnancy-associated breast cancer: results from the Korean Breast Cancer society registry database. Breast 
Cancer Res Treat. 2018;172(1):113-21. https://doi.org/10.1007/s10549-0184908-6.

17. Johansson AL, Andersson TM, Hsieh CC, Jirstrom K, Dickman P, Cnattingius $\mathrm{S}$, Lambe M. Stage at diagnosis and mortality in women with pregnancyassociated breast cancer (PABC). Breast Cancer Res Treat. 2013;139(1):18392. https://doi.org/10.1007/s10549-013-2522-1.

18. Ali SA, Gupta S, Sehgal R, Vogel V. Survival outcomes in pregnancy associated breast cancer: a retrospective case control study. Breast J. 2012; 18(2):139-44. https://doi.org/10.1111/j.1524-4741.2011.01201.x.

19. Dimitrakakis C, Zagouri F, Tsigginou A, Marinopoulos S, Sergentanis TN, Keramopoulos A, Zografos GC, Ampela K, Mpaltas D, Papadimitriou C, Dimopoulos MA, Antsaklis A. Does pregnancy-associated breast cancer imply a worse prognosis? A matched case-case study. Breast Care (Basel). 2013;8(3):203-7. https://doi.org/10.1159/000352093.

20. Madaras L, Kovács KA, Szász AM, Kenessey I, Tőkés A-M, Székely B, Baranyák Z, Kiss O, Dank M, Kulka J. Clinicopathological features and prognosis of pregnancy associated Breast Cancer - a matched case control study. Pathol Oncol Res. 2013;20(3):581-90. https://doi.org/10.1007/s12253-013-9735-9.

21. Sanchez C, Acevedo F, Medina L, Ibanez C, Razmilic D, Elena Navarro M, Camus M. Breast cancer and pregnancy: a comparative analysis of a Chilean cohort. Ecancermedicalscience. 2014;8:434. https://doi.org/10.3332/ecancer. 2014.434.

22. Gooch JC, Chun J, Kaplowitz E, Guth A, Axelrod D, Shapiro R, Roses D, Schnabel F. Pregnancy-associated breast cancer in a contemporary cohort of newly diagnosed women. Breast J. 2019. https://doi.org/10.1111/tbj. 13510.

23. Suleman $\mathrm{K}$, Osmani AH, Al Hashem H, Al Twegieri T, Ajarim D, Jastaniyah $N$, Al Khayal W, Al Malik O, Al Sayed A. Behavior and outcomes of pregnancy associated Breast Cancer. Asian Pac J Cancer Prev. 2019;20(1):135-8. https:// doi.org/10.31557/APJCP.2019.20.1.135.

24. Bae SY, Jung SP, Jung ES, Park SM, Lee SK, Yu JH, Lee JE, Kim SW, Nam SJ. Clinical characteristics and prognosis of pregnancy-associated Breast Cancer: poor survival of luminal B subtype. Oncology. 2018;95(3):163-9. https://doi. org/10.1159/000488944.

25. Kim YG, Jeon YW, Ko BK, Sohn G, Kim EK, Moon Bl, Youn HJ, Kim HA, Korean Breast Cancer S. Clinicopathologic characteristics of pregnancy-associated Breast Cancer: results of analysis of a Nationwide Breast Cancer registry database. J Breast Cancer. 2017;20(3):264-9. https:/doi.org/10.4048/jbc.2017.20.3.264.

26. Johansson ALV, Andersson TML, Hsieh C-C, Jirström K, Cnattingius S, Fredriksson I, Dickman PW, Lambe M. Tumor characteristics and prognosis in women with pregnancy-associated breast cancer. Int J Cancer. 2018; 142(7):1343-54. https://doi.org/10.1002/ijc.31174.

27. Daling JR, Malone KE, Doody DR, Anderson BO, Porter PL. The relation of reproductive factors to mortality from breast cancer. Cancer Epidemiol Biomark Prev. 2002;11(3):235-41.

28. Moreira WB, Brandao EC, Soares AN, Lucena CE, Antunes CM. Prognosis for patients diagnosed with pregnancy-associated breast cancer: a paired casecontrol study. Sao Paulo Med J. 2010;128(3):119-24.

29. Mathelin C, Annane K, Treisser A, Chenard MP, Tomasetto C, Bellocq JP, Rio MC. Pregnancy and post-partum breast cancer: a prospective study. Anticancer Res. 2008;28(4C):2447-52.

30. Yang YL, Chan KA, Hsieh FJ, Chang LY, Wang MY. Pregnancy-associated breast cancer in Taiwanese women: potential treatment delay and impact on survival. PLoS One. 2014;9(11):e111934. https://doi.org/10.1371/journal. pone.0111934.

31. Halaska MJ, Pentheroudakis G, Strnad P, Stankusova H, Chod J, Robova H, Petruzelka L, Rob L, Pavlidis N. Presentation, management and outcome of 32 patients with pregnancy-associated breast cancer: a matched controlled study. Breast J. 2009;15(5):461-7. https://doi.org/10.1111/j.1524-4741.2009.00760.x

32. Johansson AL, Andersson TM, Hsieh CC, Cnattingius S, Lambe M. Increased mortality in women with breast cancer detected during pregnancy and different periods postpartum. Cancer Epidemiol Biomark Prev. 2011;20(9): 1865-72. https://doi.org/10.1158/1055-9965.EPI-11-0515.

33. Hahn KM, Johnson PH, Gordon N, Kuerer H, Middleton L, Ramirez M, Yang W, Perkins G, Hortobagyi GN, Theriault RL. Treatment of pregnant breast cancer patients and outcomes of children exposed to chemotherapy in utero. Cancer. 2006;107(6):1219-26. https://doi.org/10.1002/cncr.22081.

\section{Publisher's Note}

Springer Nature remains neutral with regard to jurisdictional claims in published maps and institutional affiliations.

\section{Ready to submit your research? Choose BMC and benefit from}

- fast, convenient online submission

- thorough peer review by experienced researchers in your field

- rapid publication on acceptance

- support for research data, including large and complex data types

- gold Open Access which fosters wider collaboration and increased citations

- maximum visibility for your research: over $100 \mathrm{M}$ website views per year

At BMC, research is always in progress.

Learn more biomedcentral.com/submissions 